\title{
Effects of isoflavone on oxidative stress parameters and homocysteine in postmenopausal women complaining of insomnia
}

\author{
LETÍCIA C. BRANDÃO ${ }^{1}$, HELENA HACHUL ${ }^{1}$, LIA R. BITTENCOURT ${ }^{1}$, EDMUND C. \\ BARACAT $^{2}$, SERGIO TUFIK $^{1}$ AND VÂNIA D'ALMEIDA ${ }^{1,3}$
}

\author{
${ }^{1}$ Department of Psychobiology. \\ 2 Department of Gynecology. \\ ${ }^{3}$ Department of Biosciences. \\ Universidade Federal de São Paulo (UNIFESP-EPM), São Paulo-SP, Brazil.
}

\begin{abstract}
Sleep disorders have an increased incidence after menopause. The objective of this work was to evaluate the effects of isoflavone on some oxidative stress markers in postmenopausal women complaining of insomnia. Women aged between 50-65 years $(n=38)$ were recruited and assigned to a double-blind placebo controlled study for 4 months. The treated group received $100 \mathrm{mg}$ /day of isoflavones. Blood collections were conducted on three different occasions to assess total glutathione; superoxide dismutase and catalase in erythrocytes; lipid peroxidation; and homocysteine plasma concentrations. No differences between the groups were observed. However, all the patients seem to improve their oxidative stress status and homocysteine concentration after treatment. Superoxide dismutase activity was correlated with age and time of menopause at the beginning of the treatment, but these correlations were no longer observed by the end of the study. Soy isoflavones were not able to overcome the placebo effect for either oxidative stress parameters or homocysteine concentrations.
\end{abstract}

Key terms: homocysteine, isoflavones, insomnia, menopause, oxidative stress.

\section{A) INTRODUCTION}

The prevalence of sleep disturbances increases as women approach and undergo through menopause (Hachul et al., 2008) and the most common complaints are insomnia (Shaver and Zenk, 2000), poor sleep efficiency (Baker et al., 1997), difficulty in maintaining sleep (Woodward and Freedman, 1994), breathing irregularity (Saaresranta et al., 2001), and hot flashes. Studies have reported an incidence of insomnia between $28 \%$ and $63 \%$ in postmenoupausal women (Kuh et al., 1997; von Muhlen et al., 1995), while in women above 30 years old it varies between $26 \%$ and 45\% (Carskadon et al., 1976; Shaver et al., 1991).
Furthermore, it is also well known that cardiovascular risk progressively increases after menopause, and that blood homocysteine concentration is considered an independent risk factor for cardiovascular disease.

It has already been demonstrated that total homocysteine is higher in postmenopausal than premenopausal women (Hak et al., 2000), and that Hormonal Therapy (HT) seems to decrease homocysteine levels (Madsen et al., 2002). However, this therapy has also been demonstrated to be harmful by increasing the risk of cardiovascular diseases (CVD) and breast cancer (Rossouw et al., 2002).

Some authors found a tendency in women who initiated hormone therapy 
closer to menopause to have reduced CVD risk compared with the increase in CVD risk among women further from menopause (Rossouw et al., 2007). Thus, beginning treatment early, along with some other options in the therapies adopted among menopausal women, could be important for preventing high incidence of CVD.

Despite the benefits of hormone therapy, increased thromboembolic events and breast cancer were described in the Women's Health Initiative (WHI) study among women undergoing HT for five years (Rossouw et al., 2002). In this sense, the use of alternative therapies has been proposed. Some of the most recently studied medications are isoflavones. These are phytoestrogens, i.e., plant compounds, whose phenolic ring is similar to $17 \beta$ estradiol and that can bind to the estrogen receptor with a decreased affinity (Kuiper et al., 1997).

Several studies have evaluated the effects of isoflavones on cardiovascular risk in postmenopausal women. While some authors described an improvement (Bairey Merz et al., 2006; Nagata et al., 2003), others have not observed any changes (Cheng et al., 2007; Hanson et al., 2006).

Isoflavones have also been reported to have important antioxidant properties (RuizLarrea et al., 1997); although the antioxidant effects of these substances under normal conditions are still controversial. Djuric and colleagues (Djuric et al., 2001) found that the levels of 5-hydroxymethyl-2'deoxyuridine (5-OHmdU) in nucleated blood cells were significantly decreased in healthy women after one week of soy isoflavone supplementation, and remained low during the three weeks of their study. On the other hand, some authors (Hsu et al., 2001) have observed no differences in erythrocyte superoxide dismutase levels (SOD) or glutathione peroxidase levels (GPx) in postmenopausal Chinese women.

A frequent and related menopausal symptom that could possibly affect oxidative stress parameters is inadequate sleep. Reimund (Reimund, 1994) has hypothesized that cerebral free radicals accumulate during wakefulness and are removed during sleep. Nevertheless, experimental studies have found controversial results when oxidative stress parameters and sleep were analyzed. Some of these findings show that no alterations occur in the levels of cerebral antioxidant enzymes of rats after $96 \mathrm{~h}$ of sleep deprivation (D'Almeida et al., 1997), while others show evidence of decreases in glutathione levels in some brain regions (D'Almeida et al., 1997); changes in antioxidant enzyme activities in rat livers and hearts (Everson et al., 2005); and changes in antioxidant defense of fruit flies during different stages of the sleep-wake cycle (Cirelli, 2006).

The aim of this work was to investigate the effect of isoflavone on a plasma homocysteine concentration and oxidative stress parameters (plasma lipid peroxidation, erythrocyte SOD and catalase activities, and total glutathione) in postmenopausal women complaining of insomnia.

\section{B) MATERIALS AND METHODS}

\section{Study subjects}

Thirty-eight postmenopausal women complaining of insomnia, who had attended the Sleep Institute, São Paulo, Brazil, were recruited using advertisements in a local newspapers, as well as TV and radio broadcasts. They had been previously selected with regard to their sleep complaints. All subjects included in this study met DSM IV (American Psychiatric Association, 2000) criteria for insomnia. Apnea was defined as an airflow reduction of at least $80 \%$ and hypopnea as an airflow reduction greater than $50 \%$, or less if associated with a $3 \%$ desaturation or arousal. Such events were counted if they lasted more than 10 seconds (American Academy of Sleep Medicine, 1999). The score on the apnea-hypopnea index (AHI) referred to the number of apnea or hypopnea events per hour of sleep (a score $<10$ being considered in the normal range). Their age varied between 50 and 65 years, with at least 1 year of amenorrhea, serum follicle stimulating hormone (FSH) levels above $30 \mathrm{mIU} / \mathrm{mL}$, and a body mass index of 30 or less. 
Subjects had not been under HT or sleep-inducing medication. Women with hard-control diabetes mellitus, recent heart attack or thromboembolitic diseases, severe blood hypertension, severe or active liver failure, as well as those with endometrial echoes above $5 \mathrm{~mm}$ upon ultrasound evaluation or endometrial cancer were excluded from the sample. In addition, women with atypical mammary hyperplasia or breast cancer were also excluded. All women gave written consent after detailed explanation of the study.

At the beginning of the protocol, all women attended a lecture together about the study and the importance of not changing habits during the study. They were advised that the physician should be warned if any of their habits possibly changed (i.e. medication use, exercises, diet). The patients were randomized in two groups (placebo and isoflavone - $n=19$, per group). The study was double-blind and placebo-controlled, and all the subjects were asked to be at the Institute once a month to receive a supply of isoflavones or placebo sufficient to last until their next visit. All women were advised to eat as they normally would.

The tablets of Fisiogen $₫$ (provided by Zambon Group) contained $200 \mathrm{mg}$ of Glycine max, which corresponded to $80 \mathrm{mg}$ of isoflavone $(60.8 \mathrm{mg}$ of genistein, $16 \mathrm{mg}$ of daidzein and $3.2 \mathrm{mg}$ of glicitein). Indistinguishable pills without any active ingredients were given to the placebo group. The patients were told to take one pill per day. The treatment lasted 4 months.

\section{Approval by Medical Research and Ethics Committee}

The scientific content and ethical dimensions of the research protocols and consent forms were approved by the Medical Research and Ethics Committee of UNIFESP/EPM (Proc. \#0564/02).

\section{Experimental procedures}

Venous blood was collected on three different occasions during the study (at the beginning, after 2 months, and at the end of the treatment).
To access lipid peroxidation, we analyzed the levels of thiobarbituric acid reactive substances (TBARS) in plasma by a colorimetric assay $(\lambda=535 \mathrm{~nm})$ (Ohkawa et al., 1979). The results were expressed as nanomoles of malondyaldehyde/mL (nmol/ $\mathrm{mL}$; desirable levels for women are below 2.0).

A catalase assay was carried out following the method described by Adamo and co-workers (Adamo et al., 1989). Hemolysate samples were used, and a decrease in absorbance at $230 \mathrm{~nm}$ was observed. Activity values were expressed as units/mg of hemoglobin (U/mg $\mathrm{Hb}$ ). SOD was assayed using the method described by McCord and Fridovich (McCord and Fridovich, 1969). A decrease in absorbance at $550 \mathrm{~nm}$ was observed, and the activity was calculated as $\mathrm{U} / \mathrm{mg} \mathrm{Hb}$. A total glutathione assay was carried out using Tietze's method (Tietze, 1969). Total glutathione concentrations were obtained spectrophotometrically at $412 \mathrm{~nm}$ and results expressed as $\mathrm{mmol} / \mathrm{g} \mathrm{Hb}$.

Total plasma homocysteine concentrations were obtained by the method described by Pfeiffer et al. (Pfeiffer et al., 1999) using high-performance liquid chromatography (HPLC) with fluorimetric detection and isocratic separation. Homocysteine concentrations were given in $\mu \mathrm{mol} / \mathrm{L}$ (normal range 5-15 $\mu \mathrm{mol} / \mathrm{L}$ ).

\section{Statistical analysis}

The results were presented as mean \pm standard deviation. The repeated measures analysis of variance (ANOVA) test was used to compare the two groups (placebo and isoflavone) during the treatment. The level of significance was set at $\mathrm{p}=0.05$. Pearson correlation analysis was carried out to compare the correlation between SOD values and the years of menopause before and after the treatment.

\section{C) RESULTS AND DISCUSSION}

All patients were followed until the end of the study. No patient dropped out or reported changes of habit during the protocol. We also did not observe any differences between 
the placebo and isoflavone groups for the biochemical parameters measured (Table 1). Despite our previous work showing that some clinical data, such as time of onset of menopause, may be correlated to oxidative stress status, probably due to a lack of estrogen (Hachul de Campos et al., 2006), no improvement in these parameters was observed after isoflavone administration. Our results corroborate those described by Hsu and colleagues (Hsu et al., 2001), who did not find differences in SOD and glutathione peroxidase levels after isoflavone supplementation, and also with Hanson and co-workers (Hanson et al., 2006), who found no differences in homocysteine levels with isoflavone administration, although none of these studies specifically selected postmenopausal patients with insomnia.

Despite the fact that there were no differences between the groups, it is evident that for some of the variables studied there was a group-independent improvement (i.e., diminution in TBARS levels after 4 months and increase in total glutathione concentrations after 2 and 4 months). This may indicate that isoflavone did not have a sufficient effect to overcome the improvements caused by the placebo effect with respect to these biochemical factors.

It is still controversial to what extent isoflavone supplementation could be considered a therapy for menopausal symptoms (Cassidy et al., 2006). Although the effects of isoflavones on the parameters we have chosen are still controversial, our results are in agreement with some previous works

Another interesting aspect of the study was the negative correlations between SOD and time of menopause and SOD and age that we found in the baseline. These correlations became positive and statistically insignificant after treatment with both placebo and isoflavone (Figure 1).

Russouw and colleagues (Rossouw et al., 2007) found that women who initiated hormone therapy closer to menopause tend to have reduced CVD risk compared to the increase in CVD risk among women more distant from menopause, but this trend did not meet their criterion for statistical significance. We hypothesize that the mechanisms related to this increase in CVD risk in non-treated women could be determined by changes in some antioxidant parameters, since there is a negative

TABLE 1

Biochemical parameters in both groups analyzed at three different periods. Data are presented as mean \pm standard deviation.

\begin{tabular}{|c|c|c|c|c|}
\hline & Baseline & After 2 months & After 4 months & p-value \\
\hline $\begin{array}{l}\text { TBARS }(\mathrm{nmol} / \mathrm{mL}) \\
\text { placebo } \\
\text { isoflavone }\end{array}$ & $\begin{array}{l}2.61 \pm 1.11 \\
2.63 \pm 0.56\end{array}$ & $\begin{array}{l}2.89 \pm 1.04 \\
2.51 \pm 1.05\end{array}$ & $\begin{array}{l}1.99 \pm 0.71 \\
1.63 \pm 0.63\end{array}$ & $\mathrm{p}=0.59$ \\
\hline $\begin{array}{l}\mathrm{SOD}(\mathrm{U} / \mathrm{mg} \mathrm{Hb}) \\
\text { placebo } \\
\text { isoflavone }\end{array}$ & $\begin{array}{l}13.93 \pm 1.83 \\
13.80 \pm 2.13\end{array}$ & $\begin{array}{l}10.29 \pm 2.54 \\
11.08 \pm 2.09\end{array}$ & $\begin{array}{l}11.73 \pm 3.29 \\
10.49 \pm 2.63\end{array}$ & $\mathrm{p}=0.17$ \\
\hline $\begin{array}{l}\text { Catalase }(\mathrm{U} / \mathrm{mg} \mathrm{Hb}) \\
\text { placebo } \\
\text { isoflavone }\end{array}$ & $\begin{array}{l}81.64 \pm 23.61 \\
83.27 \pm 28.80\end{array}$ & $\begin{array}{l}80.53 \pm 14.84 \\
81.53 \pm 13.27\end{array}$ & $\begin{array}{l}110.81 \pm 16.74 \\
106.69 \pm 18.00\end{array}$ & $\mathrm{P}=0.88$ \\
\hline $\begin{array}{l}\mathrm{t}-\mathrm{GSH}(\mu \mathrm{mol} / \mathrm{g} \mathrm{Hb}) \\
\text { placebo } \\
\text { isoflavone }\end{array}$ & $\begin{array}{l}6.01 \pm 1.02 \\
6.32 \pm 1.17\end{array}$ & $\begin{array}{l}7.50 \pm 1.28 \\
7.55 \pm 1.19\end{array}$ & $\begin{array}{l}6.88 \pm 0.98 \\
7.16 \pm 0.91\end{array}$ & $\mathrm{p}=0.67$ \\
\hline $\begin{array}{l}\mathrm{HCY}(\mu \mathrm{mol} / \mathrm{L}) \\
\text { placebo } \\
\text { isoflavone }\end{array}$ & $\begin{array}{l}12.46 \pm 3.00 \\
10.94 \pm 1.85\end{array}$ & $\begin{array}{c}11.16 \pm 4.30 \\
9.25 \pm 1.73\end{array}$ & $\begin{array}{l}11.22 \pm 2.65 \\
10.41 \pm 2.24\end{array}$ & $\mathrm{p}=0.37$ \\
\hline
\end{tabular}


correlation between age or time of menopause and the activity of SOD, an important antioxidant enzyme. Interestingly, when the duration of treatment with isoflavone or placebo increases, the correlation with SOD activity disappears, suggesting that both treatments influence antioxidant parameters. This finding could indicate that the correlation between two variables (age and SOD activity / time of menopause and SOD activity) could be undone by a clinical approach.

Concerning the improvement in some of the parameters observed in both groups, we propose that it may be due to a placebo effect. It has been shown that the placebo effect may even lead to endogenous

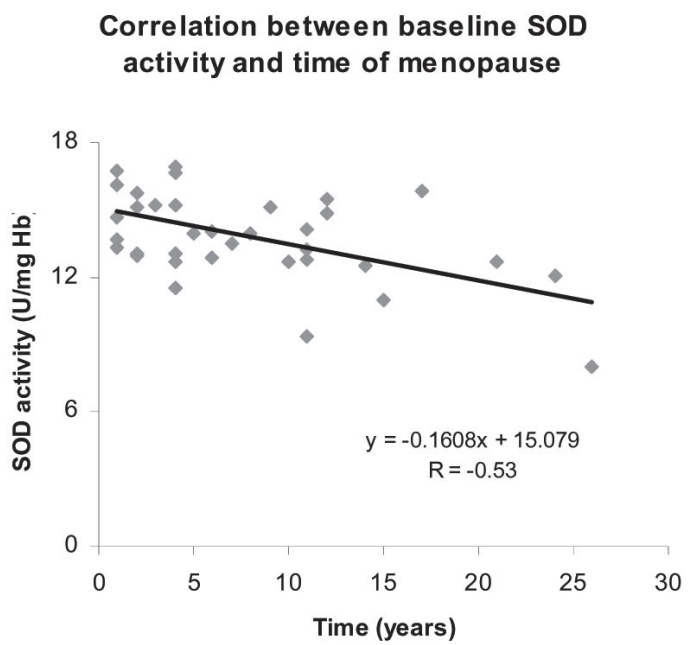

Correlation between baseline SOD activity and age

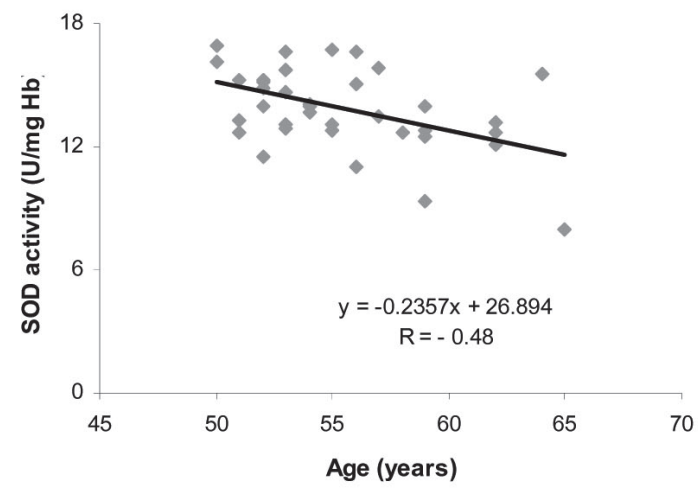

hormone production in some cases (Benedetti et al., 2003). It is possible that these women could be more susceptible to placebo effects because they have volunteered to take part in the research; optimism is one factor that may change the response to a placebo (Geers et al., 2007).

The most interesting data is that a placebo effect, which occurred with both treatments, was apparently able to undo a correlation between biochemical and physical data (Figure 1). This absence of correlation after the treatment was observed even when the placebo and isoflavone groups were evaluated separately (data not shown). Another aspect of the study that we can point out is that menopausal women

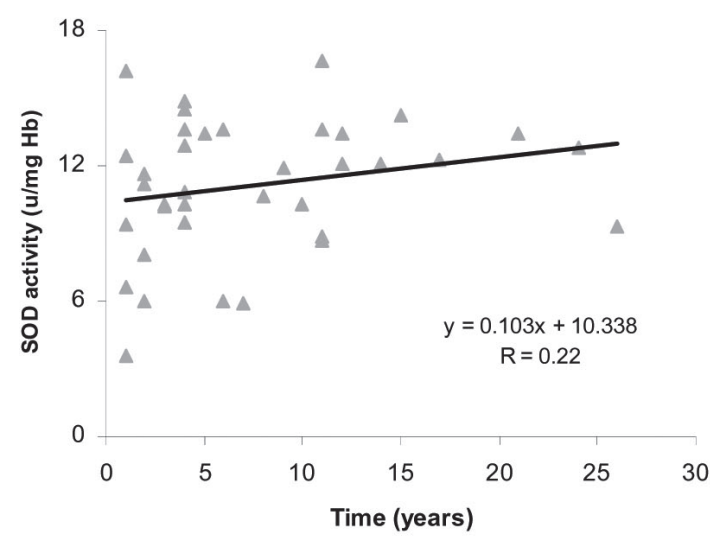

\section{Correlation between SOD activity in the end of treatment and age}

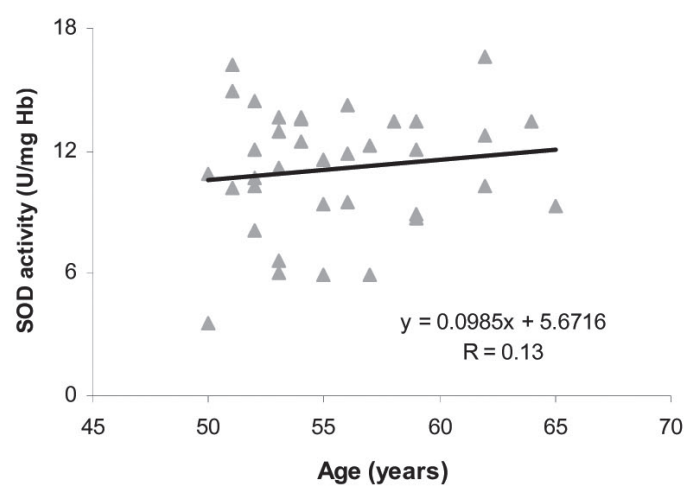

Figure 1: Effects of the treatment on the correlation between SOD activity and time of menopause, and also SOD activity and age of patients. 
may be a population more susceptible to placebo effects, as they have just entered in a new phase of life, full of hormonal, physical, social and mental changes.

A good alternative to minimize the placebo effect would be the application of the open-hidden paradigm (in which the individual either totally views a treatment or receives it in a "hidden" way). This seems to be the most ethical and effective manner to design the studies, although it is not easy to adapt this model in all clinical circumstances (Colloca et al., 2004). Further studies are needed to investigate to what extent the placebo effect can actually improve biochemical parameters in postmenopausal women.

\section{D) CONCLUSIONS}

Soy isoflavones were not able to overcome the placebo effect for either oxidative stress parameter measured or for homocysteine concentration in postmenopausal women.

\section{E) ACKNOWLEDGEMENTS}

This study was supported by grants from FAPESP (CEPID), CNPq, AFIP FADAUNIFESP and Zambon Group. The authors would like also to thank Vanessa Gonçalves Pereira, Maria Aparecida Oliveira, Jeniffer Oliveira and Jornal da Paulista for their helpful assistance.

\section{REFERENCES}

AMERICAN ACADEMY OF SLEEP MEDICINE (1999) Sleep-related breathing disorders in adults: recommendations for syndrome definition and measurement techniques in clinical research. The Report of an American Academy of Sleep Medicine Task Force. Sleep, 22: 667-689

AMERICAN PSYCHIATRIC ASSOCIATION (2000) Diagnostic and Statistical Manual of Mental Disorders - DSM-IV. American Psyciatric Publishing, 4th edition

ADAMO AM, LLESUY SF, PASQUINI JM, BOVERIS A (1989) Brain chemiluminescence and oxidative stress in hyperthyroid rats. Biochem J, 263: 273-277

BAIREY MERZ CN, JOHNSON BD, BRAUNSTEIN GD, PEPINE CJ, REIS SE, PAUL-LABRADOR M, HALE G, SHARAF BL, BITTNER V, SOPKO G, KELSEY SF (2006) Phytoestrogens and lipoproteins in women. J Clin Endocrinol Metab, 91: 2209-2213
BAKER A, SIMPSON S, DAWSON D (1997) Sleep disruption and mood changes associated with menopause. J Psychosom Res, 43: 359-369

BENEDETTI F, POLLO A, LOPIANO L, LANOTTE M, VIGHETTI S, RAINERO I (2003) Conscious expectation and unconscious conditioning in analgesic, motor, and hormonal placebo/nocebo responses. J Neurosci, 23: 4315-4323

CARSKADON MA, DEMENT WC, MITLER MM, GUILLEMINAULT C, ZARCONE VP, SPIEGEL R (1976) Self-reports versus sleep laboratory findings in 122 drug-free subjects with complaints of chronic insomnia. Am J Psychiatry, 133: 1382-1388

CASSIDY A, ALBERTAZZI P, LISE NIELSEN I, HALL W, WILLIAMSON G, TETENS I, ATKINS S, CROSS H, MANIOS Y, WOLK A, STEINER C, BRANCA F (2006) Critical review of health effects of soyabean phyto-oestrogens in post-menopausal women. Proc Nutr Soc, 65: 76-92

CHENG G, WILCZEK B, WARNER M, GUSTAFSSON JA, LANDGREN BM (2007) Isoflavone treatment for acute menopausal symptoms. Menopause, 14: 468-473

CIRELLI C (2006) Sleep disruption, oxidative stress, and aging: new insights from fruit flies. Proc Natl Acad Sci U S A, 103: 13901-13902

COLLOCA L, LOPIANO L, LANOTTE M, BENEDETTI F (2004) Overt versus covert treatment for pain, anxiety, and Parkinson's disease. Lancet Neurol, 3: 679-684

D'ALMEIDA V, HIPOLIDE DC, AZZALIS LA, LOBO LL, JUNQUEIRA VB, TUFIK S (1997) Absence of oxidative stress following paradoxical sleep deprivation in rats. Neurosci Lett, 235: 25-28

DJURIC Z, CHEN G, DOERGE DR, HEILBRUN LK, KUCUK O (2001) Effect of soy isoflavone supplementation on markers of oxidative stress in men and women. Cancer Lett, 172: 1-6

EVERSON CA, LAATSCH CD, HOGG N (2005) Antioxidant defense responses to sleep loss and sleep recovery. Am J Physiol Regul Integr Comp Physiol, 288: R374-383

GEERS AL, KOSBAB K, HELFER SG, WEILAND PE, WELLMAN JA (2007) Further evidence for individual differences in placebo responding: an interactionist perspective. J Psychosom Res, 62: 563-570

HACHUL DE CAMPOS H, BRANDAO LC, D'ALMEIDA $\mathrm{V}$, GREGO BH, BITTENCOURT LR, TUFIK S, BARACAT EC (2006) Sleep disturbances, oxidative stress and cardiovascular risk parameters in postmenopausal women complaining of insomnia. Climacteric, 9: 312-319

HACHUL H, BITTENCOURT LR, ANDERSEN ML, HAIDAR MA, BARACAT EC, TUFIK S (2008) Effects of Hormone Therapy with Estrogen and/or Progesterone on Sleep Pattern in Postmenopausal Women. Int J Gynaecol Obstet (in press)

HAK AE, POLDERMAN KH, WESTENDORP IC, JAKOBS C, HOFMAN A, WITTEMAN JC, STEHOUWER CD (2000) Increased plasma homocysteine after menopause. Atherosclerosis, 149: 163-168

HANSON LN, ENGELMAN HM, ALEKEL DL, SCHALINSKE KL, KOHUT ML, REDDY MB (2006) Effects of soy isoflavones and phytate on homocysteine, C-reactive protein, and iron status in postmenopausal women. Am J Clin Nutr, 84: 774-780

HSU CS, SHEN WW, HSUEH YM, YEH SL (2001) Soy isoflavone supplementation in postmenopausal women. Effects on plasma lipids, antioxidant enzyme activities and bone density. J Reprod Med, 46: 221-226

KUH DL, WADSWORTH M, HARDY R (1997) Women's 
health in midlife: the influence of the menopause, social factors and health in earlier life. $\mathrm{Br} \mathrm{J}$ Obstet Gynaecol, 104: 923-933

KUIPER GG, CARLSSON B, GRANDIEN K, ENMARK E, HAGGBLAD J, NILSSON S, GUSTAFSSON JA (1997) Comparison of the ligand binding specificity and transcript tissue distribution of estrogen receptors alpha and beta. Endocrinology, 138: 863-870

MADSEN JS, KRISTENSEN SR, KLITGAARD NA, BLADBJERG EM, ABRAHAMSEN B, STILGREN L, JESPERSEN J (2002) Effect of long-term hormone replacement therapy on plasma homocysteine in postmenopausal women: a randomized controlled study. Am J Obstet Gynecol, 187: 33-39

MCCORD JM, FRIDOVICH I (1969) Superoxide dismutase. An enzymic function for erythrocuprein (hemocuprein). J Biol Chem, 244: 6049-6055

NAGATA C, SHIMIZU H, TAKAMI R, HAYASHI M, TAKEDA N, YASUDA K (2003) Soy product intake is inversely associated with serum homocysteine level in premenopausal Japanese women. J Nutr, 133: 797-800

OHKAWA H, OHISHI N, YAGI K (1979) Assay for lipid peroxides in animal tissues by thiobarbituric acid reaction. Anal Biochem, 95: 351-358

PFEIFFER CM, HUFF DL, GUNTER EW (1999) Rapid and accurate HPLC assay for plasma total homocysteine and cysteine in a clinical laboratory setting. Clin Chem, 45: 290-292

REIMUND E (1994) The free radical flux theory of sleep. Med Hypotheses, 43: 231-233

ROSSOUW JE, PRENTICE RL, MANSON JE, WU L, BARAD D, BARNABEI VM, KO M, LACROIX AZ, MARGOLIS KL, STEFANICK ML (2007) Postmenopausal hormone therapy and risk of cardiovascular disease by age and years since menopause. Jama, 297: 1465-1477
ROSSOUW JE, ANDERSON GL, PRENTICE RL, LACROIX AZ, KOOPERBERG C, STEFANICK ML, JACKSON RD, BERESFORD SA, HOWARD BV, JOHNSON KC, KOTCHEN JM, OCKENE J (2002) Risks and benefits of estrogen plus progestin in healthy postmenopausal women: principal results From the Women's Health Initiative randomized controlled trial. Jama, 288: 321-333

RUIZ-LARREA MB, MOHAN AR, PAGANGA G, MILLER NJ, BOLWELL GP, RICE-EVANS CA (1997) Antioxidant activity of phytoestrogenic isoflavones. Free Radic Res, 26: 63-70

SAARESRANTA T, POLO-KANTOLA P, RAUHALA E, POLO O (2001) Medroxyprogesterone in postmenopausal females with partial upper airway obstruction during sleep. Eur Respir J, 18: 989-995

SHAVER JL, ZENK SN (2000) Sleep disturbance in menopause. J Womens Health Gend Based Med, 9: 109-118

SHAVER JL, GIBLIN E, PAULSEN V (1991) Sleep quality subtypes in midlife women. Sleep, 14: 1823

TIETZE F (1969) Enzymic method for quantitative determination of nanogram amounts of total and oxidized glutathione: applications to mammalian blood and other tissues. Anal Biochem, 27: 502522

VON MUHLEN DG, KRITZ-SILVERSTEIN D, BARRETT-CONNOR E (1995) A communitybased study of menopause symptoms and estrogen replacement in older women. Maturitas, 22: 71-78

WOODWARD S, FREEDMAN RR (1994) The thermoregulatory effects of menopausal hot flashes on sleep. Sleep, 17: 497-501 
